\title{
Cultivo experimental de Tigriopus sp. (Copepoda: Harpacticoidea)
}

\author{
Armando Mujica R., Cecilia Carvajal U. y Osvaldo Miranda E. \\ Facultad de Ciencias del Mar \\ Universidad Católica del Norte \\ Casilla 117, Coquimbo, Chile
}

\begin{abstract}
RESUMEN. Tigriopus sp. es un copépodo de pozas intennareales de la IV Región (Chile), de hábitos bento-pelágicos y muy resistente a cambios de temperatura, salinidad y contenido de oxígeno disuelto. Entre otras, estas características han despertado el interés por estudiar la factibilidad biológica del cultivo de esta especie, a fin de alimentar larvas de peces y crustáceos de interés comercial, con un alimento vivo que se encuentre en su dieta natural. En el presente estudio se entregan los resultados obtenidos en el cultivo experimental de esta especie, referidos a crecimiento poblacional, fecundidad, estado de desarrollo, alimentación, temperatura y salinidad.

El mayor crecimiento se logró con la combinación de $21^{\circ} \mathrm{C}$ de temperatura, $26 \%$ de salinidad y un alimento de mezcla en iguales proporciones de Nannochloris $s p$. (microalga) y Saccharomyces sp. (levadura). Se determinó que las hembras portan un promedio de 24 huevos, independiente de la talla y la camada. No hay mortalidad en la etapa de eclosión, por lo que se generaron tantos nauplios como huevos producidos. El tiempo de aparición de huevos desde el momento de la cópula fue dependiente de la temperatura, así como también la velocidad de desarrollo de las diferentes fases, apareciendo los copepoditos I a los 6-7 días después de la eclosión y los adultos aproximadamente a los 17 días.
\end{abstract}

Palabras claves: cultivo, experimental, copépodo, Tigriopus sp.

\section{Experimental culture of Tigriopus sp. (Copepoda: Harpacticoidea)}

\begin{abstract}
Tigriopus sp. is a copepod inhabiting intertidal pools in the IV Region (Chile), with bentho-pelagic behaviour and very resistant to changes in temperature, salinity and oxygen contents. These characteristics lead to the interest in studying the biological feasability of cultivation of this species to use it as nonnal food for larval fish and crustacean of commercial interest. This study gives information about the biology of this species, mainly related with growth, development, feeding, fecundity and some limiting enviromental factors (temperature and salinity).

According to this, the best population growth was obtained with a combination of $21^{\circ} \mathrm{C}$ temperature and $26 \%$ salinity, feeded with a mixture of Nannochloris sp. (microalgae) and Saccharomyces sp. (yeast). Concemig fecundity it was established that females carry on 24 eggs, no matter the size or brood. In the other hand it was possible to observe that there is no mortality at hatching time, so they produce as many nauplii as carrying eggs. The time for eggs appearance from coupling was directly related to temperature, as well as the speed of development of different stages appearing copepodite 1, 6 to 7 days after hatching and obtaining adults aproximately, 17 days after hatching.
\end{abstract}

Key words: culture, experimental, copepod, Tigriopus sp.

\section{INTRODUCCION}

En la trama trófica del mar los copépodos son el principal nexo entre los productores primarios del pélagos y los consumidores secundarios. Visto de otra manera, más del 90\% de la energía radiante en el mar es fijada por las microalgas y los principales consumidores primarios son los copépodos (Raymont, 1963). Estos diminutos crustáceos constituyen más del $70 \%$ de los componentes del zooplancton de todos los mares, salvo contadas excepciones. Estas características les significa estar en la dieta de la mayoría de los depredadores, entre los cuales se cuentan las especies que constituyen recur- 
sos cultivables, como peces y crustáceos (Gee, 1987).

Dada la importancia de la alimentación en las etapas tempranas del desarrollo de las especies cultivables, se despliegan grandes esfuerzos en este sentido. La idea es proporcionar a estas especies una alimentación balanceada, palatable y rentable, en especial en aquellas etapas críticas del desarrollo (Klein Breteler et al., 1990).

Es así como en los cultivos de peces y crustáceos en etapas larvarias se usa principalmente como alimento Artemia salina, especie de amplio rango de tolerancia a salinidades y temperaturas, además de producir huevos resistentes a la deshidratación y por ende almacenables por largos períodos. No obstante, esta especie es de un alto costo de adquisición, además de no ser un ingrediente en las dietas normales de especies cultivables. Cabe señalar que larvas en cultivo alimentadas con esta especie presentan carencias nutritivas de diferente índole (Hobb y Snell, 1987).

Los copépodos harparticoides, especialmente los del género Tigriopus que viven en pozas intermareales, muestran gran tolerancia a condiciones ambientales extremas y presentan alta fecundidad, por lo que constituyen una alternativa interesante de ser considerada en la alimentación de larvas de peces y crustáceos en cultivos (Labra de Chas, 1991). Además, los copépodos son constituyentes importantes de la dieta natural de estas larvas (Klein Breteler et al., 1990).

Las razones anteriormente expuestas han motivado el estudio de Tigriopus sp., con el propósito de proporcionar las bases que permitan desarrollar un cultivo masivo de esta especie, para ser utilizada como alimento de larvas de peces y crustáceos en cultivos.

\section{MATERIALES Y METODOS}

El trabajo experimental se realizó en los laboratorios del Centro Costero de la Universidad Católica del Norte, donde se cultivaron Tigriopus sp. a partir de ejemplares capturados en pozas intermareales del sector La Pampilla de Coquimbo (IV Región, Chile). Estos se mantuvieron en acuarios de vidrio de cinco litros, entre noviembre de 1994 y enero de 1995. La especie podría corresponder tentativamente a $T$. californicus, única del género descrita para las costas de Chile. Sin embargo, ajuicio de G. Asencio como pers.), las características morfológicas de los ejemplares capturados no coinciden plenamente con a especie descrita.

\section{Temperatura y salinidad}

Para determinar ]a temperatura y salinidad óptimas en el desarrollo de la especie, los copépodos se cultivaron en nueve tratamientos diferentes, producto de la combinación de tres temperaturas $\left(16,5^{\circ}, 21^{\circ}\right.$ y $\left.25^{\circ} \mathrm{C}\right)$, y tres sa]inidades $(26 \%$, $34,5 \%$ y $40,6 \%$ o) (Tabla 1). Estas condiciones fueron seleccionadas de acuerdo a antecedentes previamente establecidos (Mujica et al., 1990). Las temperaturas requeridas se lograron usando calentadores eléctricos provistos de dimer, mientras que para las salinidades se utilizaron diluciones y evaporaciones.

En cada uno de los tres baños termorregulados se dispusieron cuatro cápsulas de plástico de 250 mi, con $100 \mathrm{ml}$ de agua de mar filtrada a $60 \mu \mathrm{m}$. para cada una de las salinidades preestablecidas. En cada cápsula se distribuyeron veinte copépodos adultos elegidos al azar, los que fueron alimentados durante veinte días con $1 \mathrm{ml}$ de la microalga Nannochloris sp., en una concentración de aproximadamente 600.000 cél $/ \mathrm{ml}$. Cada dos días se contaron y retiraron los ejemplares muertos. Transcurrido este tiempo, se contaron los ejemplares reconociendo sexo y estado de desarrollo (machos, hem-

Tabla 1. Temperaturas y salinidades utilizadas en los diferentes tratamientos.

\begin{tabular}{|c|c|c|}
\hline Tratamientos & $\begin{array}{c}\text { Temperatura } \\
\left({ }^{\circ} \mathrm{C}\right)\end{array}$ & $\begin{array}{c}\text { Salinidad } \\
(\%)\end{array}$ \\
\hline T1S1 & 16,5 & 26,0 \\
T1S2 & 16,5 & 34,5 \\
T1S3 & 16,5 & 40,6 \\
T2S1 & 21,0 & 26,0 \\
T2S2 & 21,0 & 34,5 \\
T2S3 & 21,0 & 40,6 \\
T3S1 & 25,0 & 26,0 \\
T3S2 & 25,0 & 34,5 \\
T3S3 & 25,0 & 40,6 \\
\hline
\end{tabular}


bras, hembras ovígeras, copepoditos y adultos en cópula).

\section{Alimentación}

Veinte copépodos adultos, entre los cuales se incluyeron tres hembras portadoras de huevos, fueron cultivados en cada una de 15 cápsulas plásticas con 100 $\mathrm{ml}$ de agua de mar filtrada a $60 \mu \mathrm{m}$. Durante veinte días, a temperatura y salinidad constante de $21^{\circ} \mathrm{C}$ y $26 \%$, los copépodos se alimentaron con tres dietas diferentes. En tres grupos de cinco cápsulas cada uno, se incluyó la microalga Nannochloris sp., la levadura Saccharomyces sp. y una mezcla en proporción 1: 1 de microalga y levadura. Las dietas fueron suministradas diariamente en una concentración aproximada de $600.000 \mathrm{cél} / \mathrm{ml}$.

El alimento se obtuvo del cultivo de microalgas del Centro Costero y de levadura de panificación preparada en laboratorio. Una vez transcurrido el tiempo de experimentación se contaron los especímenes, reconociendo sexo y estado de desarrollo (adultos, hembras ovígeras, copepoditos y adultos en cópula).

\section{Consumo de alimento}

En tres cápsulas de Petri de $25 \mathrm{ml}$, conteniendo 10 $\mathrm{ml}$ de agua de mar filtrada a $60 \mu \mathrm{m}$ y concentraciones de 600.000 cél/ml de Nannochloris sp., Saccharomyces sp. y una mezcla de éstas en proporción 1:1, se distribuyeron cinco copépodos adultos elegidos al azar. Estos se mantuvieron en las cápsulas durante una hora; luego se agregaron tres gotas de formalina diluida al 5\% para detener el consumo de alimento. El recuento de células se realizó mediante un hematocitómetro de Neubahuen de 0,1 mm de profundidad.

La tasa de consumo (TC) se determinó a través de la siguiente ecuación:

$$
\mathrm{TC}=\frac{\mathrm{C}_{1}-\mathrm{C}_{2}}{\mathrm{t}_{2}-\mathrm{t}_{1}} \quad \text { (Cowles et al., 1988) }
$$

$\mathrm{C}_{1}$ : concentración de células al inicio, en el tiempo $t_{1}$

$\mathrm{C}_{2}$ : concentración de células al final, en el tiempo $t_{2}$

$t_{2}-t_{1}$ : intervalo de tiempo entre $t_{1}$ y $t_{2}$ ( 1 hora)

\section{Fecundidad}

Diez hembras ovígeras de talla conocida se dispusieron separadamente en cápsulas de Petri de $25 \mathrm{ml}$, conteniendo $15 \mathrm{ml}$ de agua de mar filtrada a $60 \mu \mathrm{m}$, hasta la liberación del saco. Luego, las hembras se retiraron de las cápsulas y los huevos fueron incubados hasta la eclosión, con el fin de contabilizarlos y medir los nauplios eclosionados.

Paralelamente se examinaron las hembras portadoras, a las cuales se les desprendió el saco mediante agujas de disección, para contar y medir los huevos bajo un estereomicroscopio. Para verificar el número de nauplios por saco, los huevos contados se dispusieron en placas de Petri hasta la eclosión de los nauplios.

\section{Velocidad de desarrollo}

En diez cápsulas plásticas de $250 \mathrm{ml}$ se dispusieron diez hembras ovígeras en $100 \mathrm{ml}$ de agua de mar, mantenidas a $21^{\circ} \mathrm{C}$ y $26 \%$. Las hembras se alimentaron diariamente con $0,1 \mathrm{ml}$ de mezcla de microalga y levadura, en una concentración aproximada de 600.000 cél $/ \mathrm{ml}$. Las hembras se examinaron dos veces al día, para determinar el momento de liberación del saco. Luego de la liberación, las hembras fueron retiradas y se rotularon las cápsulas. Diariamente y hasta alcanzar el estado adulto se observaron, contaron y midieron bajo un estereomicroscopio los diferentes estados de desarrollo.

\section{Análisis estadístico}

la comparación de los resultados obtenidos en los diferentes tratamientos (temperatura, salinidad. mortalidad y alimentación), fue realizada en base a los análisis de Kruskall- Wallis y a posteriori de MannWhitney (Sokal y Rohlf, 1979).

\section{RESULTADOS Y DISCUSION}

\section{Efectos de la temperatura y salinidad}

A partir de veinte ejemplares adultos, de los cuales tres eran hembras ovigeras, el mayor crecimiento después de veinte días de cultivo se logró con el tratamiento de temperatura intermedia y salinidad más baja (T2S1 $=21^{\circ} \mathrm{C}$ y $26 \%$ o), representando un $290 \%$ de aumento. De esta forma, el número final promedio fue de 78 ejemplares, con un máximo de 


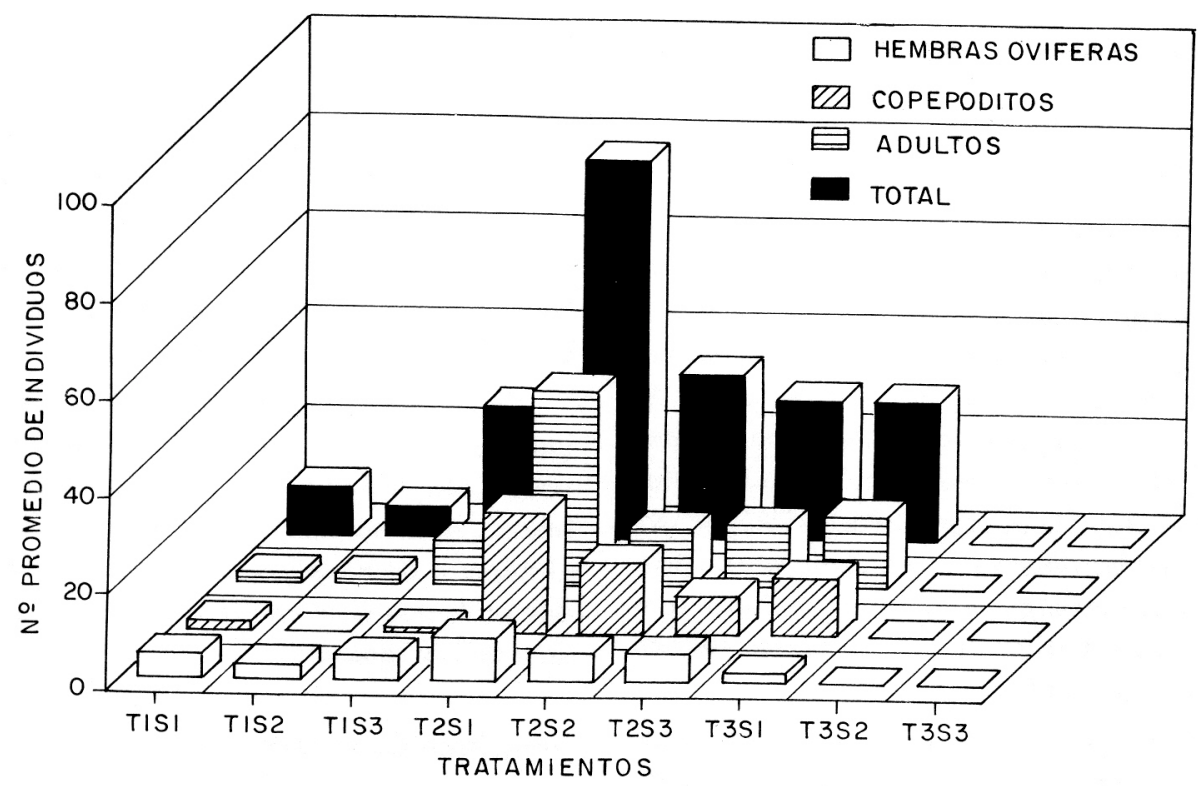

Figura 1. Crecimiento poblacional de Tigriopus sp. en distintas condiciones de temperatura y salinidad (Tabla 1).

114 y un mínimo de 59 copépodos. En estas condiciones también se logró la máxima expresión poblacional de hembras portadoras y copepoditos (Fig. 1). El número total de copépodos, total de adultos y copepoditos obtenidos con este tratamiento, fue significativamente diferente a los restantes, con la sola excepción del tratamiento T2S2 para el caso de los copepoditos (Tabla 2).

Los resultados obtenidos con los restantes tratamientos, permiten visualizar la disminución progre siva del crecimiento al mantener la temperatura $i r$ $21^{\circ} \mathrm{C}$ y aumentar la salinidad. Por el contrario, a menor y mayor temperatura $\left(16,5^{\circ}\right.$ y $\left.25^{\circ} \mathrm{C}\right)$, independientemente de las salinidades, no se logró crecimiento; se exceptúa el tratamiento $\mathrm{T} 3 \mathrm{~S} 1\left(25^{\circ} \mathrm{C}\right.$ y $26 \%$ ), con el que se obtuvo $70 \%$ de crecimiento, al igual que con el tratamiento T2S $3\left(21^{\circ} \mathrm{C}\right.$ y $40,6 \%$ o).

$\mathrm{Al}$ respecto se puede señalar, que aunque la temperatura promedio de las pozas donde se capturaron los copépodos fue menor que la que mostró el mejor crecimiento poblacional, las fluctuaciones de las mismas superan ampliamente los óptimos detectados. Respecto a la salinidad promedio, la de las pozas fue mayor que la que permitió el mayor crecimiento poblacional.

Por otra parte, los rangos usados en los experimentos están dentro de la variación experimentada en las pozas y coinciden con los rangos establecidos en los experimentos preliminares (Mujica et al., 1990).

Hirata et al. (1985), establecieron que entre las especies Tisbe sp., Amphiascella sp., Calanus sp. y Tigriopus japonicus, la última es la que ofrece me. jores ventajas para su producción masiva, dada su resistencia a cambios de temperatura $\left(10^{\circ}-27^{\circ} \mathrm{C}\right)$ y salinidad (0-18\%o).

De acuerdo a los resultados logrados en el culti. vo a diferentes temperaturas y a los establecidos previamente para Tigriopus sp. (Mujica et al., 1990), se cultivaron huevos a $21^{\circ} \mathrm{C}$. De esta manera se determinó que el tiempo que demora el desarrollo, desde la eclosión hasta el estado adulto y aparición de las primeras hembras con huevos, es de 17 días.

Además se determinó una talla media de los nauplios de $120 \mu \mathrm{m}$ y para los adultos de $1.030 \mu \mathrm{m}$. La talla de los nauplios de Tigriopus sp. coincidió con la de Tigriopus japonicus; no así la de los adultos, que serían notoriamente menores (Torrentera y Tacon, 1989).

En estas condiciones $\left(21^{\circ} \mathrm{C}\right.$ y $26 \%$ ) , el tiempo de incubación de los huevos fue de dos días y la duración del estado de nauplio de 6 días. Por último, la duración del estado de copepodito fue de 9 días. 
Tabla 2. Significancia (95\%) de las diferencias entre los tratamientos de temperatura y salinidad.

a) Número total de c|pepodos
\begin{tabular}{|c|c|c|c|c|c|c|c|c|}
\hline & T1S2 & T1S3 & T2S1 & T2S2 & T2S3 & T3S1 & T3S2 & T3S3 \\
\hline T1S1 & - & - & + & + & + & + & + & + \\
\hline T1S2 & & + & + & + & + & + & + & + \\
\hline T1S3 & & & + & + & + & - & + & + \\
\hline T2S1 & & & & + & + & + & + & + \\
\hline T2S2 & & & & & - & - & + & + \\
\hline T2S3 & & & & & & - & + & + \\
\hline T3S1 & & & & & & & + & + \\
\hline T3S2 & & & & & & & & - \\
\hline
\end{tabular}

b) Número de copepoditos
\begin{tabular}{|c|c|c|c|c|c|c|c|c|}
\hline & T1S2 & T1S3 & T2S1 & T2S2 & T2S3 & T3S1 & T3S2 & T3S2 \\
\hline T1S1 & + & - & + & + & - & - & + & + \\
\hline T1S2 & & - & + & + & + & + & - & - \\
\hline T1S3 & & & + & + & - & + & - & - \\
\hline T2S1 & & & & - & + & + & + & + \\
\hline T2S2 & & & & & - & - & + & + \\
\hline T2S3 & & & & & & - & + & + \\
\hline T3S1 & & & & & & & + & + \\
\hline T3S2 & & & & & & & & - \\
\hline
\end{tabular}

c) Número de adultos
\begin{tabular}{|c|c|c|c|c|c|c|c|c|}
\hline & T1S2 & T1S3 & T2S1 & T2S2 & T2S3 & T3S1 & T3S2 & T3S3 \\
\hline T1S1 & - & + & + & + & + & + & + & + \\
\hline T1S2 & & + & + & + & + & + & + & + \\
\hline T1S3 & & & + & - & - & + & + & + \\
\hline T2S1 & & & & + & + & + & + & + \\
\hline T2S2 & & & & & - & - & + & + \\
\hline T2S3 & & & & & & - & + & + \\
\hline T3S1 & & & & & & & + & + \\
\hline T3S2 & & & & & & & & - \\
\hline
\end{tabular}

d) Porcentaje de mortalidad.
\begin{tabular}{|l|c|c|c|c|c|c|c|c|}
\hline & T1S2 & T1S3 & T2S1 & T2S2 & T2S3 & T3S1 & T3S2 & T3S3 \\
\hline T1S1 & - & + & + & + & + & + & + & + \\
\hline T1S2 & & + & + & + & + & + & + & + \\
\hline T1S3 & & & + & + & + & - & + & + \\
\hline T2S1 & & & & - & + & + & + & + \\
\hline T2S2 & & & & & - & + & + & + \\
\hline T2S3 & & & & & & - & + & + \\
\hline T3S1 & & & & & & & + & + \\
\hline T3S2 & & & & & & & & - \\
\hline
\end{tabular}

(+) indica diferencias significativas.

(-) indica diferencias no significativas. 


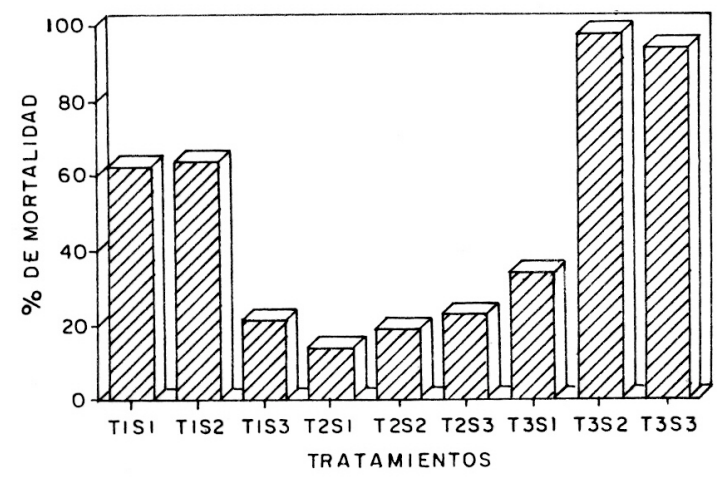

Figura 2. Mortalidad total de Tigriopus sp. en diferentes condiciones de temperatura y salinidad (Tabla 1).

\section{Mortalidad}

La mortalidad promedio obtenida de la sumatoria de las observaciones diarias de los tratamientos, presentó una relación inversa al crecimiento poblacional, coincidiendo las menores mortalidades con el mayor crecimiento (Figs. 1 y 2). Es así como la mortalidad del tratamiento T2S1 fue significativamente menor a la de los restantes tratamientos, con la sola excepción del tratamiento T2S2. Esto no es tan evidente si se considera el número de ejemplares por estado de desarrollo, en la determinación del crecimiento poblacional, bajo diferentes condiciones ambientales.

De esta forma, se puede inferir que la mortalidad fue mayor en los estados tempranos de desarrollo mantenidos a bajas temperaturas; también lo fue, aunque en menor grado, en las hembras ovígeras sometidas a salinidades medias y altas.

Se destacan los tratamientos realizados a temperatura y salinidad más alta, los cuales presentaron más del $90 \%$ de mortalidad. No obstante, con esta temperatura y $26 \%$ o de salinidad se registró una de las mortalidades más bajas.

\section{Efecto de la alimentación}

El mayor crecimiento se logró alimentando los ejemplares con mezcla de Nannochloris sp. y Saccharomyces sp., en proporción 1:1. Con este alimento se alcanzó un aumento de $490 \%$ en veinte días, lográndose un promedio de 118 ejemplares. Este incremento responde principalmente al número de copepoditos presentes; no obstante, el número de adultos muestra un aumento superior al $100 \%$. Los ejemplares de los distintos tratamientos presen-

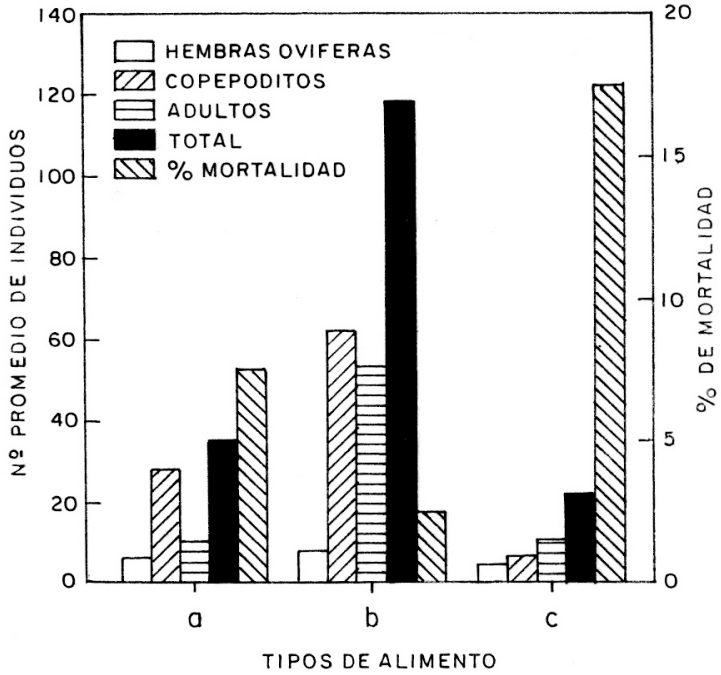

Figura 3. Crecimiento y mortalidad pobladonal de Tigriopus sp. alimentado con: a) Nannochloris sp., b) mezcla de Nannochloris sp. y de Saccharomyces sp. en proporción 1:1, y e) Saccharomyces $s p$.

taron mortalidades promedio que fluctuaron entre el 2,5 y $17,5 \%$, siendo la menor la del tratamiento alimentado con la mezcla (Fig. 3).

Los ejemplares alimentados sólo con Nannochloris sp. o con Saccharomyces sp. tuvieron un crecimiento mínimo; sin embargo, los alimentados con microalga resultaron significativamente mayores ( $p<0,05)$ (Tabla 2). Al respecto, Koga (1979) encontró diferencias notorias en el crecimiento de Tigriopus japonicus alimentado independientemente con levadura y microalgas (Nitzchia sp.).

Diversos autores han alimentado con éxito, en laboratorio, copépodos de los géneros Tisbe, Amphiascella, Calanus y Tigriopus, empleando una gran variedad de microorganismos (bacterias, fitoplancton), detritus y material orgánico de pequeño tamaño (Koga, 1979; Hirata et al., 1985; Kitajima et al., 1989a; 1989b). En general, se ha señalado que la selección del alimento debería estar determinada por el contenido nutricional que puedan aportar los copépodos en la alimentación de larvas de peces y crustáceos (Torrentera y Tacon, 1989).

En relación a la alimentación, los mejores resultados en la producción de copépodos se han encontrado al utilizar como sustrato alguna especie de macroalga de los géneros Ulva, Enteromorpha, Porphyra, entre otras. Además, éstas aportan material alimenticio y constituyen un filtro biológico que 
purifica el agua del cultivo (Torrentera y Tacon, 1989).

Hall y Bell (1993) señalan que los copépodos harpacticoides, que constituyen casi el $48 \%$ de los copépodos recolectados en Ia,s praderas marinas, utilizan las macroalgas como fuente de alimentación, hábitat y/o refugio frente a la predación, dependiendo esto último de la morfología de éstas.

Al respecto se puede señalar, que la experiencia indica lo difícil que resulta el manejo del cultivo al usar como sustrato y/o alimento algún tipo de macroalgas.

\section{Consumo de alimento}

La tasa de consumo promedio más alta fue de 1.525 cél/min y se obtuvo con individuos alimentados con Saccharomyces sp. Los individuos alimentados con mezcla y con Nannochloris $s p$. tuvieron una tasa de consumo promedio de 1.119 cél/min. Las diferencias en la tasa de consumo de los individuos alimentados con Saccharomyces sp. y con los otros dos tipos de alimento fueron estadísticamente significativas $(\mathrm{p}<0,05)$ (Tabla 2$)$.

Los valores de consumo obtenidos superan ampliamente a los resultados entregados por Cowles et al. (1988), quienes alimentaron con la microalga Thalassiosira weissflogii al copépodo calanoide Acartia tonsa. Estos autores señalan que la tasa de ingestión del zooplancton generalmente aumenta con el incremento de la abundancia fitoplanctónica y con el tamaño de la célula vegetal. La tasa de alimentación se inhibe con la presencia de células viejas, prefiriendo células vivas a células muertas. Por otra parte, Koga (1979) trabajando con Tigriopus japonicus encontró tasas de consumo del orden 350 cél/min, usando Nitzchia sp. como alimento.

La alta tasa de ingestión de alimento de estos copépodos puede ser explicada por la alta concentración de alimento suministrado (600.000 cél/ml). Las diferencias con los antecedentes disponibles pueden deberse a distintas especies de pastoreadores y al tamaño de las células usadas como alimentos. Cowles et al.(1988), señalan que la tasa de consumo también es afectada por las características químicas del alimento suministrado, aumentando el consumo cuando éstos son ricos en proteínas.

\section{Fecundidad}

La fecundidad promedio de la hembras examina- das fue de 24 huevos/ejemplar, con valores extremos de 17 y 35 huevos/ejemplar. Cabe señalar que no se establecieron relaciones entre la fecundidad y la talla. Esta última fluctuó entre 0,94 y 1,25 mm, con un promedio de $1,03 \mathrm{~mm}$ de longitud total.

La fecundidad promedio de las mismas hembras en una segunda reproducción fue de 22 huevos/ejemplar, con valores extremos similares a la primera generación. El tamaño promedio en ambas camadas fue de 0,07 $\mathrm{mm}$ y de $0,14 \mathrm{~mm}$ para los nauplios.

La mortalidad en los primeros estados fue mínima, ya que en ambas generaciones se obtuvieron tantos nauplios como número de huevos.

\section{AGRADECIMIENTOS}

Los autores agradecen a la Facultad de Ciencias del Mar de la Universidad Católica del Norte, por el financiamiento y facilidades que permitieron la ejecución de esta investigación. A la Dra. Gladys Asencio, quien gentilmente contribuyó en la identificación de la especie. En especial al Dr. Juan Enrique Illanes, por su apoyo en el desarrollo del proyecto, la revisión y comentarios del texto.

\section{REFERENCIAS BIBLIOGRAFICAS}

Cowles, T., R. Olson y S. Chisholm. 1988. Food selection by copepods: discrimination on the basis of food quality. Mar. Biol., 100: 41-49.

Gee, J.M. 1987. Impact of epibenthic predation on estuarine intertidal harpacticoid copepod populations. Mar. Biol., 96: 497-510.

Hall, M.O. y S.S. Bell. 1993. Meiofauna on the seagrass Thalassia testedinum: population eharaeteristies of harpaetieoid eopepods and assoeiations with algal epiphytes. Mar. Biol., 116: 137-146.

Hirata, H., S. Yamasaki, l. Hirata y K. Mask. 1985. Marine zooplankton eulture in a feed-baek system. Proe. Szymberk Conf. Aeuaeulture. Rept. Fae. Fish. Pref. Univ. Mie., 3: 267-318.

Hobb, F. y T. Snell. 1987. Plankton eulture manual. Florida Aqua. Farms, Ine. Date City, Florida, 125 pp.

Kitajima, C., T. Arakawa, F. Oowa, S. Ffujita, O. 
Tmada, T. Watanabe y Y. Yone. 1989a. Dietary value for red sea bream larvae of rotifer Brachionus plicatilis cultured with a new type of yeast. BuIl. Japan. Soco Sci. Fish., 46(1): 43-56.

Kitajima, C., T. Arakawa, F. Oowa, S. Ffujita, O. Tmada y T. Watanabe. 1989b. Dietary value for ayu Plecoglossus altiveris of rotifer Brachionus plicatilis cultured with bakers yeast Saccharomyces cerevisiae. BuIl. Japan. Soco Sci. Fish., 46(1): 5766.

Klein Breteler W., N. Schogt y S. González. 1990. On the role off food quality in grazing and development of life stages, and genetic change of body size during cultivation of pelagic copepods. J. Exp. Mar. Biol. Ecol., 135: 177-189.

Koga, I. 1979. Culture methods of the marine Copepods. BuIl. Japan. Soco Sci. Fish., 17(21): 32-52.

Recibido el 22 de mayo de 1995.

Aceptado el 10 de noviembre de 1995.
Labra de Chas, G. 1991. Cultivo de zooplancton. In: Acuicultura Marina Animal. Julio Coll M. (Ed.), Ediciones Mundi-Prensa, Madrid: 358365 .

Mujica, A., S. Henry, V. Andueza, y J. CortesMonroy. 1990. Fecundidad, pastoreo y tolerancia a la salinidad y temperatura de Tigriopus $s p$. (Crustacea, Copepoda). Inf. Inter., Univ. Católica del Norte, $20 \mathrm{pp}$.

Raymont, J.E.G. 1963. Plankton and productivity in the oceans. Pergamon Press, Oxford, 660 pp.

Sokal, R., y J. Rohlf. 1979. Biometría. Principios y métodos estadísticos en la investigación biológica. H. Blume Ediciones, Madrid, 833 pp.

Torrentera, L. y A. Tacon. 1989. La producción de alimento vivo y su importancia en acuacultura In: Apoyo a las actividades regionales de acuacultura para América Latina y el Caribe, Proyecto AQUILA GCPIRLA/075/ITA, FAO, Brasil, 12: 1-90. 